\title{
The effect of maturity stages of banana on the formation of acrylamide in banana fritters
}

\begin{abstract}
The effect of maturity stages of two varieties of banana (Musaparadisiaca variety Awak and $\mathrm{Abu}$ ) on the formation of acrylamide was obtained in banana fritters, the most mature banana had significantly $(\mathrm{p}<0.05)$ higher concentrations of reducing sugars; however, the concentrations of free amino acids at different maturity stages were relatively similar $(\mathrm{p}>$ 0.05). The study indicated that reducing sugars had a significant $(\mathrm{p}<0.05)$ and strong correlation $(\mathrm{R} 2=0.92$ for $\mathrm{Abu}, \mathrm{R} 2=0.82$ for Awak) with the formation of acrylamide compared to asparagine. The formation of acrylamide in both banana varieties was enhanced with an increase in both reducing sugars (glucose and fructose). This research demonstrated that the formation of acrylamide was strongly dependent on the concentration of, both glucose and fructose.
\end{abstract}

Keyword: Acrylamide; Reducing sugars; Banana 